\title{
The Translation Cycle: round and round in cycles is the only way forward for regenerative medicine
}

\author{
"... Regenerative Medicine is therefore firmly committed to supporting not only the \\ scientists, but also the translational pioneers by publishing the very best articles and \\ papers covering the entire sector."
}

Regenerative medicine involving cell-based therapies is a paradigm shift from today's biotech and pharma drugs [1]. All such disruptive technologies not only require a big scientific breakthrough, but also the necessary infrastructure to enable the successful translation into new products and services for the benefit of mankind. Thomas Edison did not just invent the light bulb, he also pioneered the necessary electricity-generating stations and distribution system to enable the light bulb to be deployed universally and thus displace oil and gas lighting. For any major scientific breakthrough to be of real value to society requires education, new experts, infrastructure and incentives $[2,3]$. The journal Regenerative Medicine is therefore firmly committed to supporting not only the scientists, but also the translational pioneers by publishing the very best articles and papers covering the entire sector. To date, well over $50 \%$ of all the content published in Regenerative Medicine has related to translation.

\section{'Translation Cycle'}

What is 'translation' and why is it important? Firstly it is definitely not a linear unidirectional process, that is bench to bedside and then stop. It is a cyclical process whereby a scientific breakthrough is given value through development, dissemination, implementation, adoption and widespread integration into the healthcare sector. Most importantly, the resulting clinical data must be fed back to the basic scientists in order to generate new hypotheses for the next round of research and translation - a continuously revolving cycle fostering advances in both basic discovery and routine clinical practice [4]. Not only does this enable the bidirectional flow of science and related technologies, but also the generation of future funding. Making a great scientific breakthrough and merely leaving it in the laboratory notebook is of no value, but produce health and wealth and the results will boost the field in every respect, including increasing funding for basic science. A win-win situation with basic scientists, bioprocess engineers, clinicians and business people not in competition but collaborative partners working towards a common goal where all will benefit, but only if all succeed.

\section{Translation gaps}

The Translation Cycle involves a number of organizations and funding mechanisms. The conventional model for new small molecule drugs or biologics prior to 2002 was that a discovery was made in the academic laboratory using government grants, spun-out into a small biotech firm funded by venture capital until successful Phase II results and then floated on the stock market or acquired by a big pharma. Unfortunately today, as we all know, this model is broken even for established therapeutic platforms let alone the emerging cell therapy sector $[5,6]$. In particular, the timescale from initial discovery to basic proof of safety (Phase I) and efficacy (Phase II) for the venture capitalist are too long; however, the main showstopper is the total lack of successful business models of how to create and capture the value. Therefore any gaps in the Translation Cycle effectively paralyse the sector's transition to becoming a dominant new international healthcare industry. The translation gaps have been clearly identified in both the USA and the UK for innovative potential new healthcare products and services by the Institute of Medicine's Clinical Research Roundtable (2000-2005) and the Cooksey Review (2006), respectively [7,8]. Both nations agree that there are two significant gaps that need to be bridged if scientific breakthroughs are going to be of benefit in healthcare and wealth creation. Whilst neither the Clinical Research Roundtable (CRR) nor Sir David Cooksey directly refer to regenerative medicine and cell-based therapies, there can be no doubt

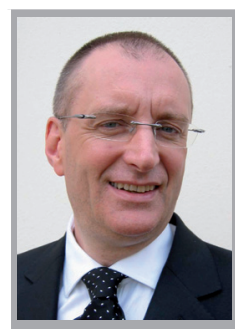

Chris Mason Author for correspondence: Advanced Centre for Biochemical Engineering, University College London, Roberts Building, Torrington Place, London, WC1E 7JE, UK Tel.: +442076790140 Fax: +442072090703 chris.mason@ucl.ac.uk

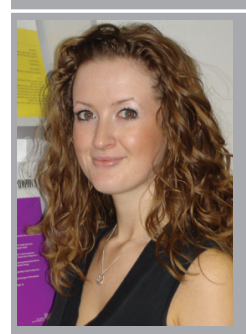

Elisa Manzotti

Future Medicine Ltd,

Unitec House, 2 Albert Place,

Finchley Central, London,

N3 1QB, UK

Tel.: +442083716090

Fax: +442083432313

e.manzotti@

futuremedicine.com;

www. futuremedicine.com

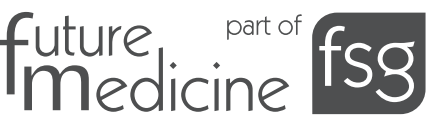


that they fall entirely under their recommendations. Figure 1 is a bespoke amalgamation based on the CRR and the Cooksey Review specifically for cell-based therapies, plus the addition of the 'reverse translation' part of the cycle in order to enable long-term sustainability and future advances. Successful clinical trials, unexpected clinical responses and even failed trials can all stimulate new hypotheses [4]. The two translation gaps (Translation Gap 1 [TG1] and Translation Gap 2 [TG2]) are both mission-critical since a missing link anywhere in the chain renders the entire chain useless.

Translation Gap 1 or the 'Valley of Death' as it is colloquially known, is the struggle with the science/technology, clinical trials, regulation and especially adequate funding to bridge the gap [9]. TG1 spans key preclinical animal studies through to the end of a successful Phase II trial. At this point, the technology has robust regulatory-approved data for safety and efficacy. The product is now de-risked to the point where it is potentially attractive to a multinational biotech, pharma and medical device company. However, the path to routine clinical deployment contains the second gap (TG2) in the Translation Cycle. TG2 is the struggle with human behavior, organizational inertia, existing healthcare infrastructure, reimbursement and resource restraints [9] that have to be overcome before a successful Phase III product can become a mainline therapy.

It is of course vital that before starting down the translational path with its escalating costs that a few simple gateway questions are first addressed, including a realistic assessment of the true market size and value, manufacturability to meet the clinical demand and the clinical performance level required to achieve the healthcare objective [10]. For a new technology to replace an incumbent its clinical performance cannot just be incrementally better but needs to be significantly superior plus ideally at a lower overall price. Costeffectiveness evaluations in healthcare rule the decision-making process, for example the guidance produced by the UK's National Institute for Health and Clinical Excellence (NICE) is based on 'good value for money, weighing up the cost and benefits of treatments' [101].

\section{The role of Regenerative Medicine}

Solving the translation gaps will undoubtedly require firm commitment by all the stakeholder groups including government [11]. Failure to implement mechanisms to close the translation gaps in a timely manner will one day ignite the perception that excessive resources are being put into stem cell research and yet where are the healthcare benefits? Biotech and pharma are already facing this challenge [12]. We must not let stem cell research, the vast majority of which is publically funded, become disconnected from the Translation Cycle. It is therefore time for a convergence of the activities of all the regenerative medicine stakeholders to embrace the Translation Cycle and build the necessary robust bridges across both TG1 and TG2. An equivalent step-change in the translation is now urgently required to match the original breakthrough science. Regenerative Medicine will be actively participating in this essential transition by being a full partner in the British Regen Industry Tool Set (BRITS) program funded by the UK's Technology Strategy Board [102]. The other collaborators are: Lonza Biologics (lead), LGC, London Regenerative Medicine Network, UCL Advanced Centre for Biochemical Engineering, UCL Department of Management Science and Innovation, and the NHS Technology Adoption Centre. BRITS is an industry-driven project aimed at establishing

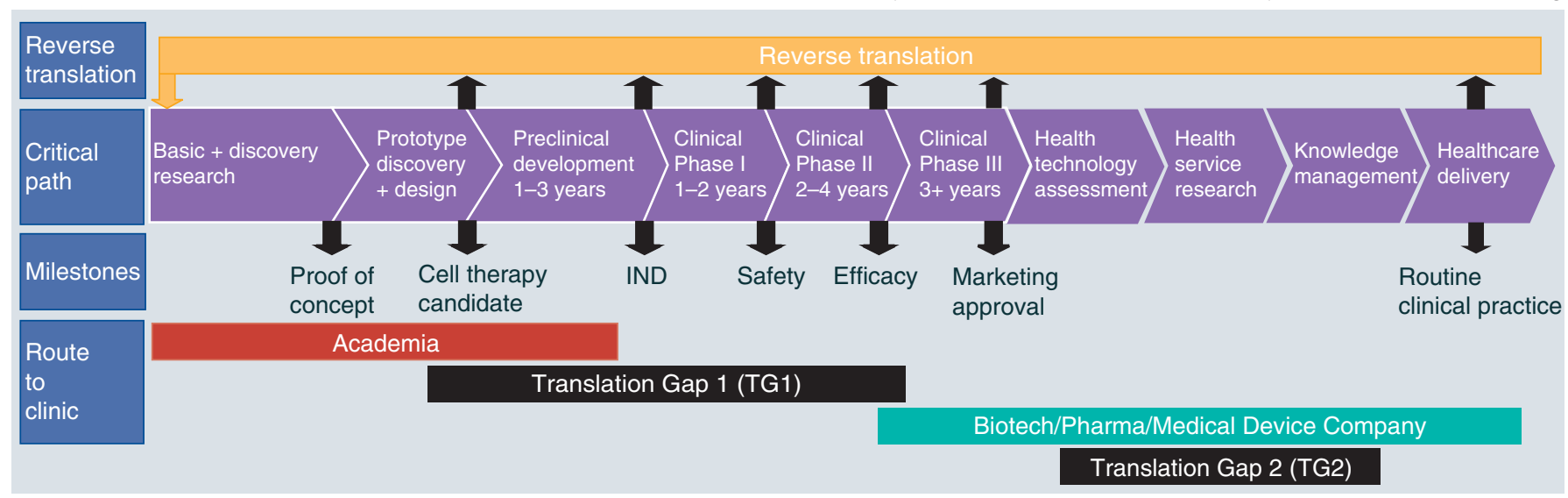

Figure 1. The Translation Cycle for cell-based therapies.

IND: Investigational New Drug Application. 
and maintaining reliable market data and then creating both detailed bioprocess economics models and higher-level business models for integration into a set of decision-support tools for widespread dissemination to all the cell therapy stakeholders. From 1 April 2010, Regenerative Medicine will not just be publishing the best research and translation, but also actively involved in helping bridge the gaps in the Translation Cycle.

\section{Financial \& competing interests disclosure}

The authors have no relevant affiliations or financial involvement with any organization or entity with a financial interest in or financial conflict with the subject matter or materials discussed in the manuscript. This includes employment, consultancies, honoraria, stock ownership or options, expert testimony, grants or patents received or pending, or royalties.

No writing assistance was utilized in the production of this manuscript.

\section{Bibliography}

1 Mason C, Manzotti E: Regen: the industry responsible for cell-based therapies. Regen. Med. 4(6), 783-785 (2009).

2 No authors listed. To thwart disease, apply now. Nature 453(7197), 823 (2008).

3 Dietz AB, Padley DJ, Gastineau DA: Infrastructure development for human cell therapy translation. Clin. Pharmacol. Ther. 82(3), 320-324 (2007).

4 Ledford H: Translational research: the full cycle. Nature 453(7197), 843-845 (2008).

5 Spack E: Minding the drug development gap. The Scientist 19(21), 36-37 (2005).

6 Klausner A: Mind the (biomedical funding) gap. Nat. Biotechnol. 23(10), 1217-1218 (2005).
7 Sung NS, Crowley WF Jr, Genel M et al.: Central challenges facing the national clinical research enterprise. JAMA 289(10), 1278-1287 (2003).

8 Cooksey D: A review of UK health research funding. HMSO, London, UK (2006).

9 Woolf $\mathrm{SH}$ : The meaning of translational research and why it matters. JAMA 299(2), 211-213 (2008).

10 Hunziker E, Spector M, Libera J et al.: Translation from research to applications. Tissue Eng. 12(12), 3341-3364 (2006).

11 Kerner JF: Knowledge translation versus knowledge integration: a "funder's" perspective. J. Contin. Educ. Health Prof. 26(1), 72-80 (2006).
12 Butler D: Translational research: crossing the valley of death. Nature 453(7197), 840-842 (2008).

\section{Websites}

101 National Institute for Health and Clinical Excellence (NICE). Our Guidance www.nice.org.uk/guidance/index.jsp

102 Technology Strategy Board press release. Regenerative Medicine research and development to receive $£ 4.5$ million funding injection. 15th January 2010 www.innovateuk.org/_assets/pdf/pressreleases/press $\% 20$ release $\% 20-\% 20$ regenmed $\% 20$ results\%2015jan10\%20final. pdf 